\title{
Retrofitting PureBallast Water Treatment Systems onboard Two Car Carriers
}

Per Warg

\section{Background}

First installed in 2003, the Alfa Laval PureBallast treatment system was installed as a retrofit and tested as full-scale prototype for three years aboard the Wallenius car carrier M/V Don Quijote. In 2008, it became the world's first chemical-free ballast water treatment system approved by the International Maritime Organization (IMO). PureBallast is a fully automated and highly effective chemical-free system for cleansing ballast water on board. It purifies the water via a combination of filtration and advanced oxidation technology (AOT). Both methods are safe for the crew and environment. Alfa Laval in cooperation with Wallenius Water, a sister company to ship ownerWallenius Lines and ship management company Wallenius Marine, developed PureBallast.

Wallenius is a family-owned Swedish shipping and logistics company with a high environmental profile. Together with subsidiaries and partners, Wallenius operates a fleet of about 135 vessels. Of these, Wallenius owns or charters some 35. Specialising in vehicle and RoRo transportation, the company strives to be ahead of environmental legislation.

The company defined these criteria for selecting a ballast water treatment system:

- Environmentally sound

- No chemicals

- No residuals

- IMO type approval

- No restriction on ballast operations

- Small footprint

- Possibility to install on existing fleet without taking vessels out of service

- Commercially available
2. Selecting the ballast water treatment system

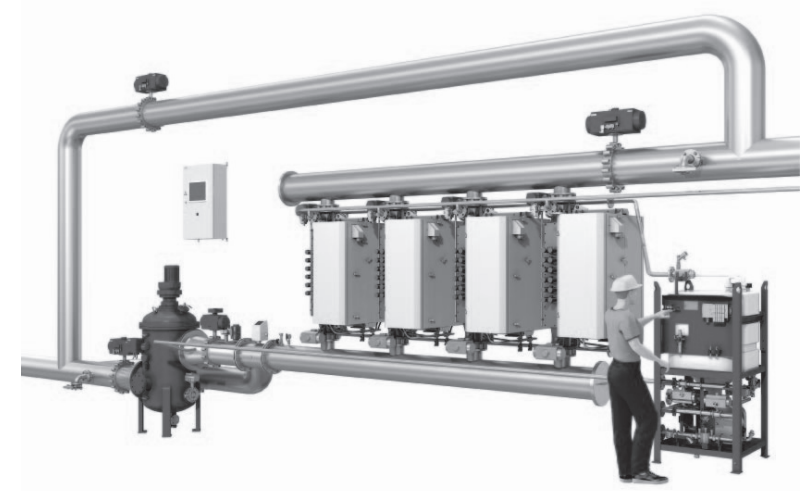

Figure 1: Ballast water treatment system "PureBallast2.0"

As a result of PureBallast's successful three-year operation onboard the $\mathrm{M} / \mathrm{V}$ Don Quijote and subsequent IMO approval, Wallenius began in 2008 installing PureBallast onboard all newbuilds and gradually retrofitting two to three existing vessels each year. This will enable the company to be in compliance with the IMO Ballast Water Convention well ahead of the projected 2016 deadline for ships with ballast capacity in excess of 5000 cubic metres.

\section{Retrofit considerations}

According to Lloyd's Register, an estimated 65,000 ships will require ballast water treatment systems retrofitting in order for the shipping industry to comply with the International Maritime Organization (IMO) Ballast Water Management Convention by 2016. Approximately 20 vessels per day must be retrofitted during 2014, the forecast peak year for retrofits. With these daunting numbers, there is no time for a wait-and-see strategy; ship owners need to determine a sound strategy for retrofitting existing vessels - and fast. 
Ulf Granlund, product specialist for PureBallast at AlfaWall, an Alfa Laval and Wallenius Water joint venture, stresses the importance of evaluating ballast water treatment systems early on. Granlund brings practical retrofitting experience to bear since he was Wallenius' environmental specialist in charge of the retrofitting the company's car carrier vessels, the $\mathrm{M} / \mathrm{V}$ Fedora and M/V Fidelio in 2008.

"It's important for ship owners to determine which vessels to begin retrofitting and then plan and execute a strategy," Granlund comments. "In the coming years we will see a peak where there will be a critical mass of retrofits being undertaken, and it will be difficult to get a hold of the ballast water treatment systems as well as qualified workers to carry out the retrofit since there is a lot of electrical and piping work involved."

According to Granlund, ship owners should carefully evaluate which system to install based on: purchase and installation costs; space and power requirements; low pressure drop over the ballast water treatment system; training costs for the crew to operate the system; ease of accessibility to system components for operation and maintenance; manufacturer guarantees; and, global coverage regarding spare parts and service engineers.

"Global availability of spare parts and service is of paramount importance," says Granlund. "Once the convention is ratified, it will be enforced by port state control officers in the same way as oily water separators and therefore must always be in good working condition."

Tablel Fact box

\begin{tabular}{|l|l|l|}
\hline & M/V FEDORA & M/V FIDELIO \\
\hline Owner & Wallenius Lines & Wallenius Lines \\
\hline Management & Wallenius Marine & Wallenius Marine \\
\hline Flag & Sweden & Sweden \\
\hline Ship type & $\begin{array}{l}\text { Large Car Truck } \\
\text { Carrier }\end{array}$ & $\begin{array}{l}\text { Large Car } \\
\text { Truck Carrier }\end{array}$ \\
\hline $\begin{array}{l}\text { Capacity car } \\
\text { (RT43) }\end{array}$ & 8000 & 8000 \\
\hline $\begin{array}{l}\text { Capacity } \\
\text { car/trucks }\end{array}$ & $3484 / 468$ & $3484 / 468$ \\
\hline
\end{tabular}

\begin{tabular}{|l|l|l|}
\hline Length $(\mathrm{m})$ & 227.8 & 227.8 \\
\hline Beam $(\mathrm{m})$ & 32.26 & 32.26 \\
\hline Draft $(\mathrm{m})$ & 11.3 & 11.3 \\
\hline Deadweight $(\mathrm{m} / \mathrm{t})$ & 30,383 & 30,383 \\
\hline Gross tonnage & 71,583 & 71,583 \\
\hline Delivered & 2008 & 2007 \\
\hline Builder & DSME & DSME Korea \\
\hline Charter & $\begin{array}{l}\text { Wallenius } \\
\text { Wilhelmsen } \\
\text { Logistics }\end{array}$ & $\begin{array}{l}\text { Wallenius } \\
\text { Wilhelmsen } \\
\text { Logistics }\end{array}$ \\
\hline
\end{tabular}

\section{Five-stage retrofit strategy}

Wallenius required that the two car carriers be retrofitted without taking them out of service because the demand in 2008 was at an all-time high. Installation took place over the course of six to nine months, and was timed to coincide with each ship's scheduled arrivals back in Europe every few months. With no off-hire for the ships, it was important to plan retrofitting carefully and deliberately in stages with a riding crew of pipe workers, welders and electricians. The vessels were operating 24/7 with virtually no idling time whatsoever.

- Stage 1-Initial preparation of ballast and cooling water piping, electrical power supply and space for the system during scheduled drydocking of the ship.

- Stage 2 - Supply the treatment system equipment on board during the ship's first scheduled return visit to Europe.

- Stage 3 - Connection of treatment system to the piping during the ship's second visit to Europe.

- Stage 4 - Conduct electrical cabling and control panel work during the ship's third visit to Europe.

- Stage 5-Commission the system and train the crew during the ship's fourth visit to Europe.

"It is, of course, in a ship owner's best interests to retrofit vessels with the minimal modifications to the existing equipment and physical structure of ship as well as with minimal disruption to ship operation," continues Granlund. "When retrofitting the M/V Fedora and M/V Fidelio, Wallenius employed a five-stage retrofit strategy to ensure that it was not 
necessary to place the vessels off-hire."

"Every time one of the vessels entered a port in the European Union, the riding crew would board and work as the vessel sailed along the European coastline," recounts Granlund. "When the vessel then reached the last port in EU, the crew would disembark and return to their regular places of employment until the vessels called at an EU port again and retrofit work could resume. The entire installation and commissioning process took place over the course of six to nine months."

While installation with a riding crew had obvious advantages of avoiding downtime productivity, it also posed challenges, including transportation of personnel and equipment and securing cabin space on board, which requires another set of planning and logistics.

\section{Stage 1: Preliminary design and engineering}

During each ship's scheduled sailing list, Granlund and his colleagues conducted the initial preparation work. This included: onboard inspection and surveying; review original drawings as well as piping and instrumentation diagrams; and identifying interfaces and integration with existing control systems. Based on the vessel type and functional requirements, the engineering team determined how a system capable of processing $1000 \mathrm{~m}^{3} / \mathrm{h}$ should be installed. In addition, the team considered other crucial factors that affect installation, such as available space for possible installation location and remote operation.

Electrical and piping requirements also play a major role in retrofitting. Electrical preparations included installation of electrical supply, preparation of automation cables to control system, preparation of remote interface and/or remote panels as well as verification of electrical load balance (or, if required, calculation of a new load balance), and verification of pump capacity (head). Piping preparations included inlet/outlet SW and LT system and discharge connection from the filter. One bypass, which enables electronic logging of ballast water activities, is part of the PureBallast system and it is highly recommended that other bypasses are not added to the system.

\section{Stage 2: Purchase and supply of the treatment system}

The system components for a PureBallast 1000 system included: control system, filter, sampling points, flow meter, CIP unit and the AOT assembly. The $3500 \times 2300-\mathrm{mm}$ installation footprint of PureBallast, which is based on a side-by-side configuration of the four AOT units that comprise the AOT assembly, fit easily into the existing space. The footprint includes access and service area as shown in Fig. 2.

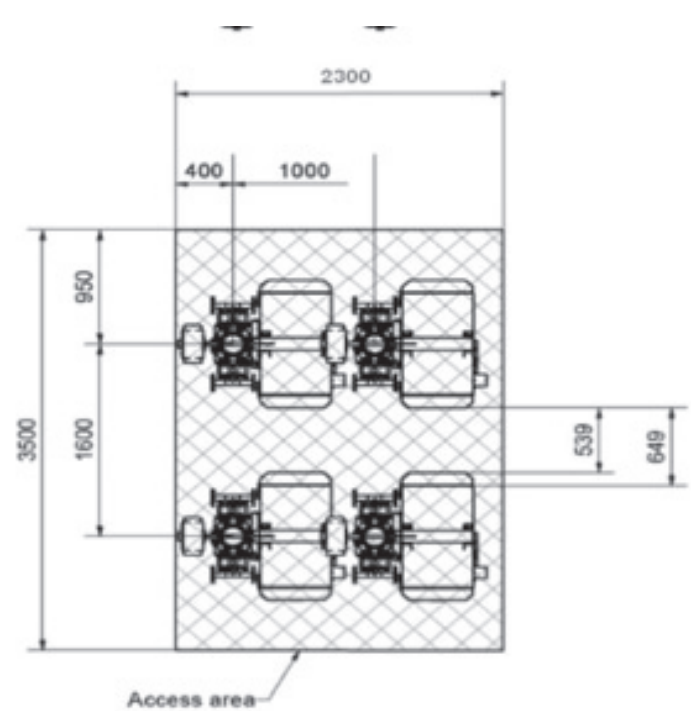

Figure 2: Installation footprint of main AOT assembly of the Alfa Laval PureBallast treatment system.
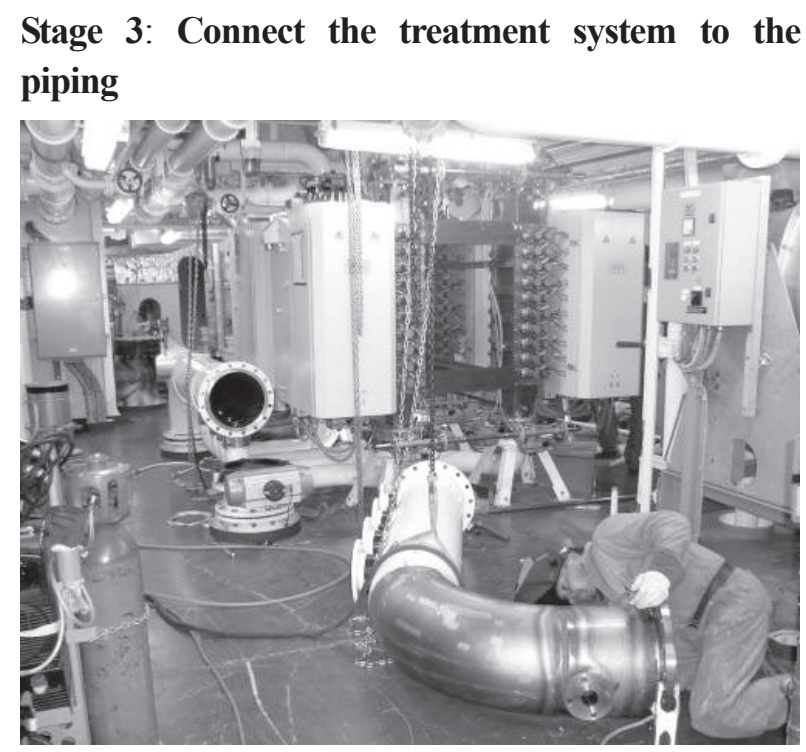

Figure 3: Work onboard to connect pipe work for the Alfa Laval PureBallast treatment system. 
All pipe work and supports were connected during the ships' second return visits to Europe. Based on the initial preparation work, most piping and supports required to install PureBallast were pre-fabricated by third-party supplier selected by Wallenius. The AOT units were transported to Helsingborg, Sweden, where the third-party supplier crafted most of the piping and supports. Some pieces, however, needed to be constructed on board in order to ensure that tensions in the pipe system were reduced.

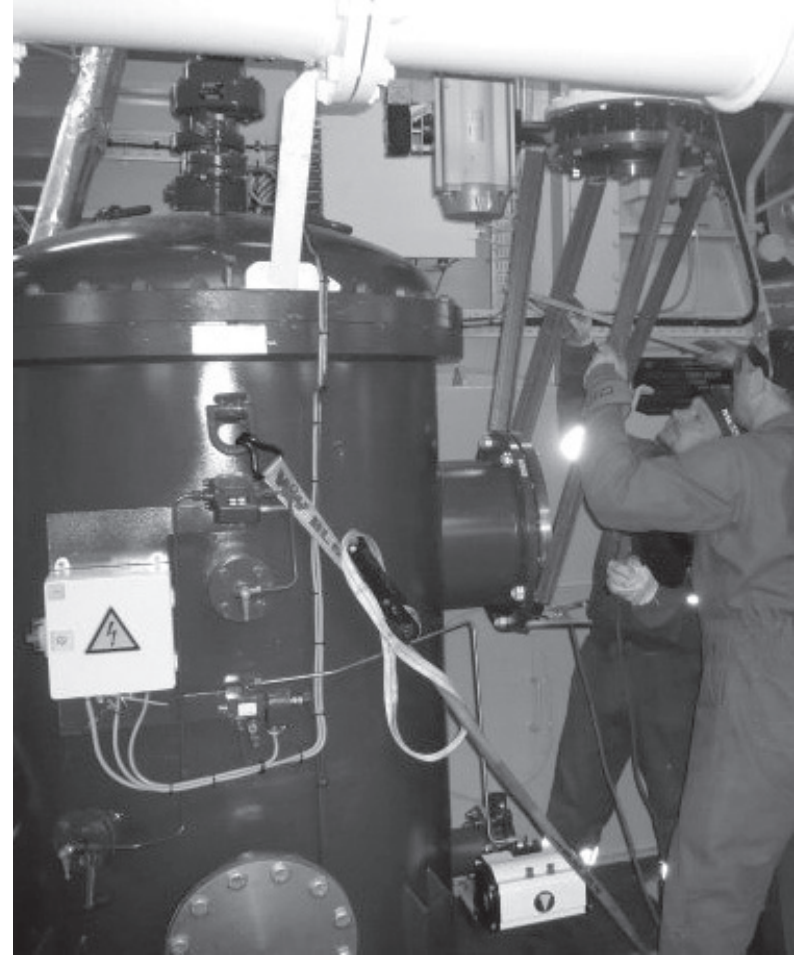

Figure 4: Ongoing work to connect the PureBallast filter unit

\section{Stage 4: Conduct electrical cabling and control panel work}

During the ships' third visits to Europe, the riding crew worked on cabling for the electrical cabinets. The electrical requirements to run PureBallast did not require the installation of additional auxiliary generators onboard. Remote control panels were installed to enable PureBallast to be started, stopped and monitored from any location onboard. The control equipment was located in the same places on board both ships, making it easier to install the system and easier for the crew to operate PureBallast when switching between vessels.

\section{Stage 5: Commission the system and train the crew} The final stage accomplished during the ships' fourth visits to Europe was commissioning the PureBallast system and training the crew to safely operate and maintain the system. Commissioning the system was easy, thanks to careful planning and installation. Onboard training for the crew was provided by Alfa Laval to ensure proper operation and maintenance of the system. This of utmost importance in order to manage safety risks and mitigate the risk of human error, which can lead to severe fines for non-compliance with ballast water regulations once they take effect and are enforced.

\section{Advances in PureBallast}

Since PureBallast received the full IMO approval in 2008 , it has been continuously improved. The most recent version of the system, PureBallast 2.0, was introduced in September 2010 and incorporates advances that further simplify installation and operation. These include:

- Lower power consumption. PureBallast 2.0 consumes $40 \%$ less power than its predecessor, making it easier for shipyards to work with the designed power on board.

- Simplified electrical system. Fewer electrical cabinets and a higher degree of integration simplify installation of the ballast water treatment system.

- Increased operating flexibility. A pause function allows ballast water treatment to be suspended briefly (e.g. during heeling). Individual AOT units can now be stopped for maintenance or to adjust the system flow.

- Control system enhancements. PureBallast 2.0 is steered via a full-colour graphical touch screen. Modbus communication allows it to be integrated with the vessel's standard interface.

- PureBallast 2.0 EX (Ex version). Ideal for tankers and other vessels with potentially explosive environments, PureBallast 2.0 EX is designed for Zone 1, group IIC and temperature class T4.

\section{Lessons learned}

Installing and commissioning PureBallast onboard the $\mathrm{M} / \mathrm{V}$ Fedora and M/V Fidelio provided Wallenius with valuable insight into addressing numerous retrofit challenges. Careful planning and scheduling were, of course, critical. Another important lesson is to establish space and power requirements very early in the process. Although space to locate the systems was readily available, Wallenius is aware 
that finding room for a system can be difficult and may involve relocating equipment onboard, cutting through steel bulkheads or other modifications. As mentioned, locating the control equipment in the same place for the two ships helps facilitate operation for the crew.

Wallenius will put these lessons to use during the next retrofit scheduled this year for the M/V Faust, sister ship to the $\mathrm{M} / \mathrm{V}$ Fedora and $\mathrm{M} / \mathrm{V}$ Fidelio, and the M/V Otello. Granlund anticipates that subsequent retrofitting will deliver significant time and cost-savings.

"There was a learning curve involved in retrofitting the Fedora and the Fidelio," says Granlund. "I expect the retrofitting of the Faust and Othello to go faster."

\section{Importance of working with a reliable retrofit partner}

Wallenius also recognizes the importance of working with a reliable partner who knows the ballast water treatment system thoroughly to do the installation work. Due to the critical mass of retrofits in the near future, Alfa Laval is now establishing strategic partnerships with companies and training personnel who can assist with design, installation and commissioning of PureBallast systems.

To date, a total of 140 PureBallast systems ranging in capacity from 250 to $2500 \mathrm{~m}^{3} / \mathrm{h}$ are in service, or have been ordered, since Alfa Laval launched the system in 2006 as one of the first systems to receive International Maritime Organization (IMO) ballast water type approval. Of these, approximately 10 percent are retrofit systems.

In addition to large car and truck carriers, PureBallast has been installed on naval ships, container vessels, bulk carriers, LPG tankers, bitumen tankers, icebreakers, offshore supply vessel and RoRo vessels. It serves as proof of Alfa Laval's ability to provide comprehensive global service and support for newbuilding and retrofit design, installation and commissioning. It also reflects the confidence that ship owners and operators have in Alfa Laval's capabilities to provide training, operation and maintenance.

For more information, please refer to www.alfalaval.com/jp
Per Warg

Business Manager PureBallast

Alfa Laval Tumba AB
Authors

\author{
Ballast
}

